\title{
Work disability and its determinants in patients with pituitary tumor- related disease
}

\author{
Daniel J. Lobatto ${ }^{1}$ - Anath N. V. Steffens ${ }^{1} \cdot$ Amir H. Zamanipoor Najafabadi ${ }^{1}$ (I) . Cornelie D. Andela ${ }^{2}$.

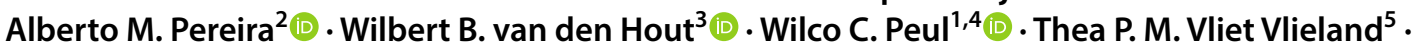 \\ Nienke R. Biermasz ${ }^{2}$ (D) Wouter R. van Furth ${ }^{1}$ (D)
}

Published online: 4 October 2018

(c) The Author(s) 2018

\begin{abstract}
Introduction Pituitary tumors may have a considerable impact on patients' functional status, including paid employment, yet research in this area is sparse.

Objective To describe work disability and its determinants in patients treated for a pituitary tumor.

Methods Cross-sectional study including patients treated for a pituitary tumor in the working age (18-65 years), who completed five validated questionnaires assessing work disability [Short Form-Health and Labour Questionnaire, Work Role Functioning Questionnaire 2.0 (WRFQ)], health-related quality of life (HRQoL) and utility (Short Form-36, EuroQoL) and disease burden (Leiden Bother and Needs Questionnaire-Pituitary). Additional data were extracted from the medical records (age, gender, tumor type, treatment, date of diagnosis) and self-reports (marital status, education, endocrine status). Associations of disease-specific and sociodemographic characteristics, HRQoL, and disease burden with (not) having a paid job were examined through multivariate logistic regression.

Results We included 241 patients (61\% female, median age 53 years, median time since diagnosis 11 years), of whom 68 (28\%) were without a paid job. Patients who had acromegaly, Cushing's disease, (pan)hypopituitarism, radiotherapy, were single, less educated, lower HRQoL, and increased disease burden were more often without a paid job $(\mathrm{p}<0.05)$. Among those with paid jobs, $41 \%$ reported health-related absenteeism in the previous year. The three work incapacitating problems reported by the largest proportion of patients were within the mental and social domain (WRFQ).

Conclusion Work disability among patients treated for a pituitary tumor is substantial. As impact on social functioning is high, it is strongly advised to incorporate work disability during clinical guidance of patients.
\end{abstract}

Keywords Pituitary adenoma $\cdot$ Work disability $\cdot$ Employment $\cdot$ Absenteeism $\cdot$ Presenteeism $\cdot$ Health-related quality of life

\begin{tabular}{|c|c|}
\hline Abbre & tions \\
\hline NFPA & Non-functioning pituitary adenoma \\
\hline ACRO & Acromegaly \\
\hline $\mathrm{CD}$ & Cushing's disease \\
\hline PRL & Prolactinoma \\
\hline
\end{tabular}

Electronic supplementary material The online version of this article (https://doi.org/10.1007/s11102-018-0913-3) contains supplementary material, which is available to authorized users.

Daniel J. Lobatto

d.j.lobatto@lumc.nl

1 Department of Neurosurgery, Leiden University Medical Center, Albinusdreef 2, 2333 ZA Leiden, The Netherlands

2 Division of Endocrinology and Center for Endocrine Tumors, Department of Medicine, Leiden University Medical Center, Leiden, The Netherlands
RCC Rathke's cleft cyst

HRQoL Health-related quality of life

SF-HLQ Short Form-Health and Labour Questionnaire WRFQ Work Role Functioning Questionnaire 2.0

SF-36 Short form-36

EQ-5D EuroQoL

LBNQ Leiden Bother and Needs Questionnaire-Pituitary

3 Medical Decision Making, Department of Biomedical Data Sciences, Leiden University Medical Center, Leiden, The Netherlands

4 Department of Neurosurgery, Haaglanden Medical Center, The Hague, The Netherlands

5 Department of Orthopedic Surgery, Leiden University Medical Center, Leiden, The Netherlands 
SD Standard deviation

IQR Interquartile range

\section{Introduction}

Even long after multimodality treatment of pituitary tumors, many patients report impairments in health-related quality of life (HRQoL) [1-3]. An important, but relatively underinvestigated domain of HRQoL is the impact of pituitary tumors on societal participation, with special regard to having or maintaining a paid job.

Our recent focus group study in patients addressing the patient's perspective on disease burden and needs for support indicated that chronic pituitary conditions have a significant impact on work and financial status [4]. In that qualitative study, several patients expressed experiencing a lack of understanding by employers, medical specialists, and occupational physicians. Some patients feared losing their jobs and therefore refrained from informing their employers/ co-workers about their disease or from mentioning it during job interviews. Furthermore, a number of patients reported not being able to continue their jobs because they could not perform the same tasks they used to do [4].

Quantitative studies on the extent of work disability in terms of having a paid job or not in this disease area are scarce. Rates of patients without a paid job vary between 36 and 74\% [5-9]; however, these studies report a variety of pituitary conditions [7-9], and/or do not exclusively comprise of patients of working age [5, 6, 8, 9], therefore affecting these rates. Determinants of having a paid job or not have not been studied extensively.

Work disability, however, not only comprises having paid employment or not; sick leave (absenteeism) or not being productive while at work (presenteeism, in some countries defined as hidden absenteeism) are also important aspects. Previous studies have reported absenteeism rates varying between 19.8 and 40.2 days per year [5,10-12], while presenteeism and perceived problems at work have never been addressed in patients with pituitary tumors. More insight into the perceived problems may help patients and healthcare providers, including occupational physicians, in guiding patients.

The objectives of this current study were to investigate (1) the rates of patients with and without a paid job treated for a pituitary tumor and of working age; (2) determinants of not having a paid job in this group; (3) loss of productivity in patients with a paid job defined as absenteeism and presenteeism; and (4) patients' perceived problems at work.

\section{Patients and methods}

\section{Study design}

This cross-sectional survey study among a cohort of patients treated for a pituitary tumor in a chronic care setting was performed between September 2016 and March 2017 at a tertiary referral center, the Leiden University Medical Center (LUMC) in the Netherlands. Institutional medical ethical review board approval was obtained prior to the start of the study (p12.067).

\section{Study population}

Patients included in this study were part of a larger crosssectional cohort $(\mathrm{N}=400)$ on long-term outcomes among patients treated for a pituitary tumor, including all patients diagnosed with a pituitary tumor (non-functioning pituitary adenoma (NFPA), acromegaly (ACRO), Cushing's disease (CD), prolactinoma (PRL) or Rathke's cleft cyst (RCC)), with sufficient Dutch language skills, more than 6 months of treatment, and currently under active followup. A subset of this study, patients between the ages of 18 and 65, was eligible for the present study. Patients were identified through the hospital registries. Diagnosis was confirmed prior to invitation by means of review of the medical record by DJL. Eligible patients were invited by a written letter to participate in this study; after written informed consent was obtained, a questionnaire was sent to all participants. In case of non-response, patients were re-approached by regular mail or by telephone.

\section{Assessments}

A set of 5 validated questionnaires was administered, including measures on work status and productivity [Short-Form-Health and Labour Questionnaire (SFHLQ)], work-related difficulties [work role functioning questionnaire 2.0 (WRFQ)], HRQoL and utility [Short Form-36 (SF-36) and EuroQoL (EQ-5D)], and perceived bother and needs for support [Leiden Bother and Needs for Support Questionnaire for pituitary patients (LBNQPituitary)], and questions on current medication usage, as well as visits to an occupational physician. The questionnaires could be filled in either digitally or on paper, both shown to provide equivalent results [13]. 


\section{Disease-specific and sociodemographic characteristics}

The disease-specific and sociodemographic characteristics were collected from the digital medical records (tumor type, date of diagnosis) and self-reports (educational level, marital status, endocrine status). This included age, sex, and hormonal status (with hypopituitarism defined as replacement of $\geq 1$ endocrine deficits, and panhypopituitarism as $\geq 2$ plus hydrocortisone replacement). Treatment was categorized arbitrarily into 4 categories: (1) no treatment (including patients with discontinued medication), (2) ongoing medical (tumor) treatment (including those with prior surgery and/or radiotherapy), (3) postoperative patients (excluding ongoing medical treatment and irradiated patients), (4) a history of radiotherapy (including prior surgery and/or discontinued medication). The categorization among patients with multimodality treatment was done according to the supposed largest ongoing impact in the current chronic setting: (1) ongoing medication (greatest impact), (2) radiotherapy, (3) past surgical intervention, (4) no therapy or temporary medical treatment (least impact). A detailed description of the treatment algorithm, which was in line with existing guidelines, has previously been published [14-16]. Level of education was categorized into low, intermediate or high, based on the guidelines of Statistics Netherlands (CBS) [17], which correspond with the International Standard Classification of Education Fields of Training and Education 2013 of the UNESCO [18].

\section{Work status}

Work status was assessed through two questionnaires: a selection of the $S F-H L Q$ was used to obtain information about employment, absenteeism and presenteeism over the past 12 months. Employment was divided into two categories: (1) having a paid job, which included part-time paid jobs, some combined with other duties such as education, taking care of the household or receiving a work disability pension; (2) not having a paid job, including engagement in any non-paid duties, education, taking care of the household, voluntary and involuntary unemployment, or early pension. The questionnaire did not differentiate whether voluntary and involuntary unemployment/early pension was due to the illness or due to other reasons. Absenteeism was defined as the number of days on sick leave over the past 12 months, presenteeism as reduced productivity while at work, and assessed by means of a question on the self-perceived performance at work on a scale of 1-10 [19].

The WRFQ assesses work disabilities and consists of 27 questions, divided into four subcategories including: work scheduling and output demands (WSOD), physical demands
(PD), mental \& social demands (MSD), and flexibility demands (FD) from which an index score was calculated. Items were scored on a 5-point rating scale: (1) all the time (100\%), (2) most of the time, (3) half of the time (50\%), (4) some of the time, (5) completely not (0\%). All items included the option "not applicable to my job" [20]. Higher scores indicate less self-perceived work disabilities.

\section{Health-related quality of life and utility}

The $S F-36$ is a 36 -item questionnaire which covers eight domains: physical function, physical role, bodily pain, general health, vitality, social function, emotional role, and mental health. These subscales range from 0 to 100 , from which the physical and mental component score can be calculated. Higher scores indicate better HRQoL [21].

The $E Q-5 D$ (5-level) consists of 5 domains: mobility, self-care, usual activities, pain/discomfort, and anxiety/ depression, from which utility (range $0-1$ ) can be calculated (EQ-5D index). The EQ-5D also includes a visual analog scale (VAS), which records self-reported health status (range $0-100)$. Higher scores indicate a better perceived health status [22].

\section{Perceived bother and needs for support}

The LBNQ-Pituitary is a disease-specific questionnaire, which was developed through focus group interviews with patients [23]. For this study, the LBNQ-Pituitary consisted of 26 items divided into five subscales: mood problems, negative illness perceptions, issues in sexual functioning, physical and cognitive complaints, and issues in social functioning, from which an index score can be calculated (range 0-100). A detailed description of how the items are scored has been previously published. Higher scores indicate a greater bother [23]. For this study we added a question on the usage of and number of visits to an occupational physician.

\section{Statistical analysis}

Data entry and control was performed through an online survey platform. All statistical analyses were performed with SPSS 23.0 software (IBM SPSS Inc., Armonk, USA). Numerical variables are presented as means and standard deviations (SD) or medians with interquartile ranges (IQR), nominal variables as frequencies with percentages.

For the univariate analysis, a Chi square test was performed for categorical variables, student's $T$ test or Mann-Whitney $U$ tests for numerical variables where applicable. Logistic regression analysis was used to determine the relationship between work status (paid job/no paid job) as a dependent factor and all possible contributing factors 
(i.e., disease-specific characteristics, sociodemographic characteristics, HRQoL). To control for confounding, variables associated with both the determinant and the outcome and not in the causal pathway of the relationship of interest were used as covariates in the multivariate analysis [24]. All determinants were corrected for age and gender, depending on the determinant also for tumor type, treatment and/ or QoL. For the work disability analysis, variables were compared between tumor types via AN(C)OVA, corrected for age and gender where applicable. For all analyses, the level of significance was set at $\mathrm{p}<0.05$ (two-sided) and associations are expressed as odds ratios (ORs) with the corresponding $95 \%$ confidence interval (CI). Missing data on the questionnaires was handled by complete case analysis due to the low amount of missings $(<5 \%)$.

\section{Results}

\section{Study population (Fig. 1)}

A total of 1667 patients were identified from the hospital registry. After exclusion of ineligible patients, letters were sent to 772 patients (including patients $>65$ years), enrolling a total of $400(51.8 \%)$ patients of whom 241 (60.2\%) patients between 18 and 65 years of age.

\section{Patient characteristics (Table 1)}

The 241 patients ( $61 \%$ female) included in the study had a median age of 53.0 (IQR 45.0-59.5) years. Median time since diagnosis was 11.4 (IQR 5.2-20.5) years and almost half of the patients were highly educated (48\%). Tumor type was: (1) NFPA in 65 patients (27\%), (2) ACRO in 41 patients (17\%), (3) CD in 32 patients (13\%), (4) PRL in 97 patients (40\%), and (5) RCC in 6 patients (3\%). Many patients had undergone multimodality treatment, with most patients in the surgical group (40\%), followed by ongoing
Fig. 1 Flow chart of in-/exclusion of patients with a pituitary tumor

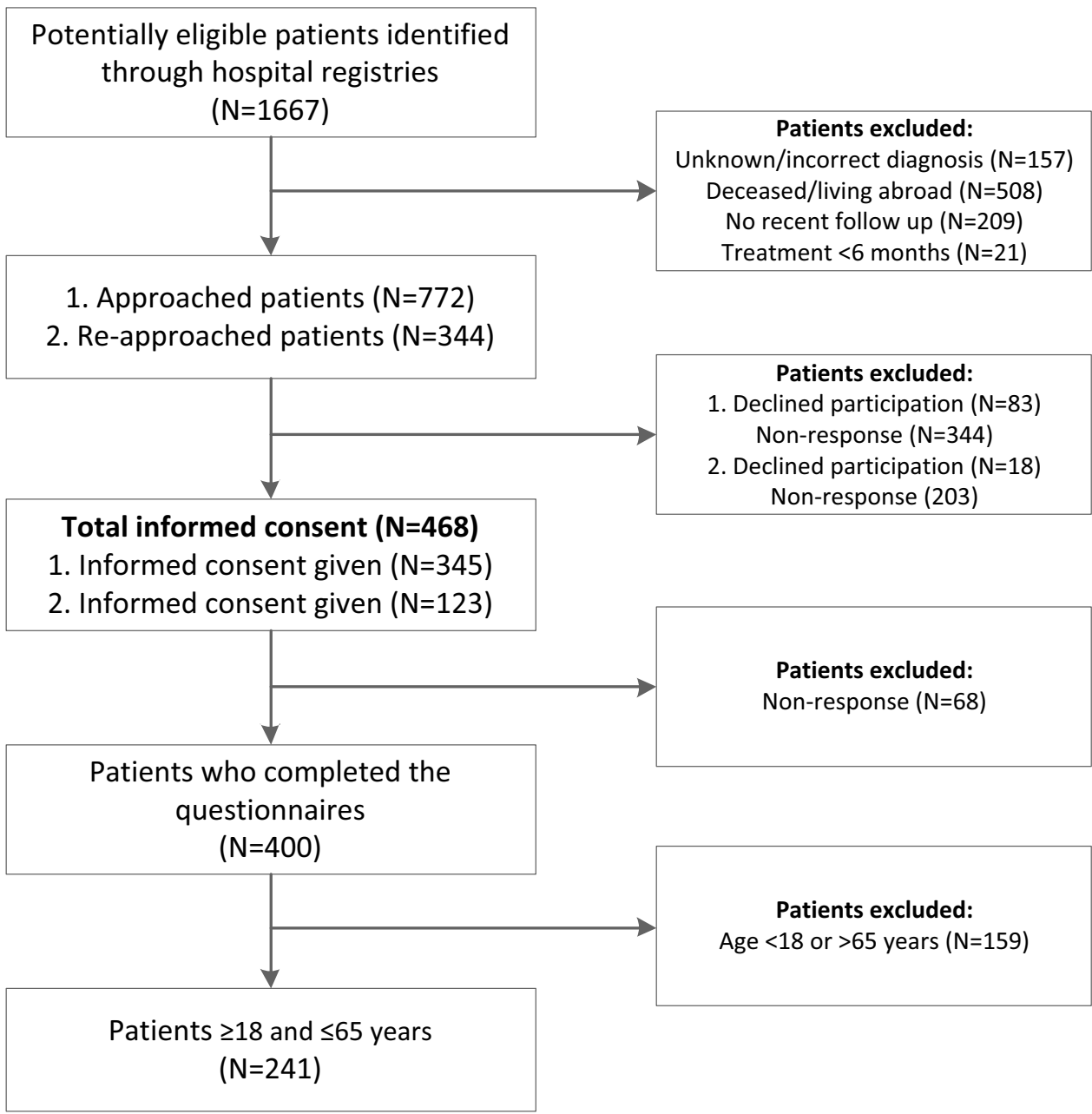


Table 1 Characteristics of 241 patients with a pituitary tumor and of working age and comparisons between those working and not working

\begin{tabular}{|c|c|c|c|c|}
\hline & $\begin{array}{l}\text { Total } \\
(\mathrm{N}=241)\end{array}$ & $\begin{array}{l}\text { No paid job } \\
(\mathrm{N}=68)\end{array}$ & $\begin{array}{l}\text { Paid job } \\
(\mathrm{N}=173)\end{array}$ & P-value \\
\hline \multicolumn{5}{|l|}{ Sociodemographic characteristics } \\
\hline Female gender, N (\%) & $147(61.0)$ & $44(32.0)$ & $103(68.0)$ & 0.459 \\
\hline Age in years, median (IQR) & $53.0(45.0-59.5)$ & $54.7(45.6-60.7)$ & $52.4(44.9-59.2)$ & 0.114 \\
\hline \multicolumn{5}{|l|}{ Marital status, $\mathrm{N}(\%)$} \\
\hline Relationship/married & $190(79.2)$ & $48(70.6)$ & $142(82.6)$ & 0.040 \\
\hline \multicolumn{5}{|l|}{ Education, N (\%) } \\
\hline Low & $65(27.0)$ & $27(39.7)$ & $38(22.0)$ & \multirow[t]{3}{*}{$<0.001$} \\
\hline Intermediate & $60(24.9)$ & $22(32.4)$ & $38(22.0)$ & \\
\hline High & $115(47.7)$ & $19(27.9)$ & $96(55.5)$ & \\
\hline \multicolumn{5}{|l|}{ Disease-specific characteristics } \\
\hline \multicolumn{5}{|l|}{ Tumor type, $\mathrm{N}(\%), \%$ per tumor type } \\
\hline NFPA & $65(27.0)$ & $15(23.1)$ & $50(76.9)$ & \multirow[t]{5}{*}{0.021} \\
\hline ACRO & $41(17.0)$ & $16(39.0)$ & $25(61.0)$ & \\
\hline $\mathrm{CD}$ & $32(13.3)$ & $15(46.9)$ & $17(53.1)$ & \\
\hline PRL & $97(40.2)$ & $20(20.6)$ & $77(79.4)$ & \\
\hline $\mathrm{RCC}$ & $6(2.5)$ & $2(33.3)$ & $4(66.7)$ & \\
\hline Time since diagnosis in years, median (IQR) & $11.4(5.2-20.5)$ & $10.8(5.1-19.0)$ & $13.7(6.6-23.8)$ & 0.204 \\
\hline \multicolumn{5}{|l|}{ Treatment, N (\%) } \\
\hline No treatment/discontinued medication & $36(14.9)$ & $6(8.8)$ & $30(17.3)$ & \multirow[t]{4}{*}{0.022} \\
\hline Ongoing medication & $75(31.1)$ & $17(25.0)$ & $58(33.5)$ & \\
\hline Surgery & $96(39.8)$ & $29(42.6)$ & $67(38.7)$ & \\
\hline Radiotherapy & $34(14.1)$ & $16(23.5)$ & $18(10.4)$ & \\
\hline \multicolumn{5}{|l|}{ Endocrine status, N (\%) } \\
\hline No deficits & $112(46.5)$ & $18(26.5)$ & $94(54.3)$ & \multirow[t]{3}{*}{$<0.001$} \\
\hline Hypopituitarism & $84(34.9)$ & $34(50.0)$ & $50(28.9)$ & \\
\hline Panhypopituitarism & $45(18.7)$ & $16(23.5)$ & $29(16.8)$ & \\
\hline \multicolumn{5}{|l|}{ HRQoL and disease bother } \\
\hline EQ-5D score, mean $(\mathrm{SD})^{\mathrm{a}}$ & $0.908(0.08)$ & $0.862(0.12)$ & $0.926(0.06)$ & $<0.001$ \\
\hline EQ-5D VAS, mean $(S D)^{a}$ & $73.32(20.7)$ & $63.88(19.1)$ & $77.02(20.1)$ & $<0.001$ \\
\hline SF-36 PCS, mean (SD) ${ }^{a}$ & $46.53(10.5)$ & $39.91(11.5)$ & $49.13(8.9)$ & $<\mathbf{0 . 0 0 1}$ \\
\hline SF-36 MCS, mean $(S D)^{\mathrm{a}}$ & $47.84(12.0)$ & $44.41(13.3)$ & $49.19(11.1)$ & 0.005 \\
\hline LBNQ-pituitary total score, mean $(\mathrm{SD})^{\mathrm{b}}$ & $17.37(18.9)$ & $25.99(20.8)$ & $13.98(17.0)$ & $<0.001$ \\
\hline
\end{tabular}

Due to rounding, not all percentages of the categorical variables add up to $100 \%$

Bold- $\mathrm{p}<0.05$

$N F P A$ non-functioning pituitary adenoma, $A C R O$ acromegaly, $C D$ Cushing's disease, $P R L$ prolactinoma, $R C C$ Rathke's cleft cyst, $N$ number, $S D$ standard deviation, IQR interquartile range, EQ-5D EuroQoL, $S F-36$ short form-36, LBNQ-Pituitary Leiden bother and needs questionnairepituitary, VAS visual analogue scale, $M C S$ mental component scale, $P C S$ physical component scale

${ }^{a}$ Higher scores indicate better HRQoL

${ }^{\mathrm{b}}$ Lower scores indicate lower disease burden

medical therapy (31\%). (Pan)hypopituitarism was present in $129(54 \%)$ of patients.

\section{Work status (Table 1)}

Sixty-eight (28\%) patients did not have a paid job. This proportion was highest in patients with Cushing's disease $(15 / 32,47 \%)$ and lowest in patients with a prolactinoma $(20 / 97,21 \%)$. Those without a job did not differ with respect to age [median age of 54.7 (45.6-60.7) years] compared to those with a job [median age of 52.4 (44.9-59.2) years], however, there was a tendency to a lower education level ( $40 \%$ vs. $22 \%$ low education, intermediate $32 \%$ vs. $22 \%$ ), and more endocrine deficits ( $74 \%$ vs. $46 \%$ ) (Table 1). The following reasons were reported for not having a paid job: 1) being a scholar/student (3\%), taking care of the household (31\%), receiving an early pension (9\%), having a (partial) disability pension (41\%) or another reason [i.e. involuntary 
Table 2 Univariate and multivariate analysis of determinants for not having a paid job among pituitary tumors of working age

\begin{tabular}{|c|c|c|c|c|c|c|c|c|c|}
\hline \multirow[t]{2}{*}{ Determinant } & \multicolumn{3}{|c|}{ Crude } & \multicolumn{3}{|c|}{$\begin{array}{l}\text { Adjusted for disease-specific and } \\
\text { sociodemographic characteristics }\end{array}$} & \multicolumn{3}{|c|}{$\begin{array}{l}\text { Adjusted for disease-specific, } \\
\text { sociodemographic characteristics } \\
\text { and HRQoL }\end{array}$} \\
\hline & OR & $95 \% \mathrm{CI}$ & p-value & OR & $95 \% \mathrm{CI}$ & p-value & OR & $95 \% \mathrm{CI}$ & $\mathrm{p}$-value \\
\hline Female gender & 1.25 & $0.70-2.23$ & 0.460 & - & - & - & - & - & - \\
\hline Age & 1.02 & $0.99-1.05$ & 0.218 & - & - & - & - & - & - \\
\hline \multicolumn{10}{|c|}{ Marital status (ref: relationship/married) ${ }^{\mathrm{a}}$} \\
\hline Single/divorced/widow & 1.97 & $1.03-3.79$ & 0.042 & 2.27 & $1.15-4.49$ & 0.019 & 1.77 & $0.80-3.87$ & 0.157 \\
\hline \multicolumn{10}{|l|}{ Education (ref: high) ${ }^{\mathrm{a}}$} \\
\hline Intermediate & 3.59 & $1.79-7.21$ & $<0.001$ & 3.43 & $1.70-6.93$ & 0.001 & 2.13 & $0.96-4.75$ & 0.064 \\
\hline Low & 2.93 & $1.42-6.01$ & 0.003 & 2.99 & $1.45-6.17$ & 0.003 & 3.31 & $1.48-7.42$ & 0.004 \\
\hline \multicolumn{10}{|l|}{ Tumor type (ref: PRL) ${ }^{\mathrm{a}}$} \\
\hline NFPA & 1.16 & $0.54-2.47$ & 0.710 & 1.11 & $0.50-2.44$ & 0.803 & 0.84 & $0.35-2.04$ & 0.698 \\
\hline ACRO & 2.46 & $1.11-5.47$ & 0.027 & 2.73 & $1.19-6.29$ & 0.018 & 1.96 & $0.77-4.99$ & 0.161 \\
\hline $\mathrm{CD}$ & 3.40 & $1.45-8.00$ & 0.005 & 3.25 & $1.38-7.67$ & 0.007 & 2.86 & $1.10-7.45$ & $\mathbf{0 . 0 3 2}$ \\
\hline $\mathrm{RCC}$ & 1.93 & $0.33-11.27$ & 0.468 & 1.68 & $0.28-9.97$ & 0.566 & 0.97 & $0.13-7.34$ & 0.979 \\
\hline Time since diagnosis ${ }^{\mathrm{b}}$ & 1.02 & $0.99-1.05$ & 0.154 & 1.00 & $0.96-1.03$ & 0.860 & 1.02 & $0.98-1.05$ & 0.375 \\
\hline \multicolumn{10}{|c|}{ Treatment (ref: no treatment) ${ }^{c}$} \\
\hline Ongoing medication & 1.47 & $0.52-4.10$ & 0.467 & 1.35 & $0.45-4.00$ & 0.594 & 1.25 & $0.37-4.22$ & 0.716 \\
\hline Surgery & 2.16 & $0.81-5.76$ & 0.122 & 1.55 & $0.50-4.77$ & 0.445 & 1.43 & $0.41-5.05$ & 0.576 \\
\hline Radiotherapy & 4.44 & $1.47-13.42$ & 0.008 & 3.87 & 1.11-13.45 & $\mathbf{0 . 0 3 3}$ & 3.04 & $0.74-12.51$ & 0.123 \\
\hline \multicolumn{10}{|c|}{ Endocrine status (ref: no deficits) ${ }^{\mathrm{b}}$} \\
\hline Hypopituitarism & 3.55 & $1.82-6.92$ & $<\mathbf{0 . 0 0 1}$ & 3.76 & $1.84-7.68$ & $<0.001$ & 3.97 & $1.77-8.88$ & 0.001 \\
\hline Panhypopituitarism & 2.88 & $1.31-6.36$ & 0.009 & 2.87 & $1.16-7.12$ & 0.023 & 2.94 & $1.06-8.17$ & 0.039 \\
\hline
\end{tabular}

Included for HRQoL: EQ-index, MCS, PCS, LBNQ-P index

Bold- $\mathrm{p}<0.05$

Ref reference category, $O R$ odds ratio, $C I$ confidence interval

${ }^{a}$ Adjusted for age, gender (HRQoL)

${ }^{\mathrm{b}}$ Adjusted for age, gender, tumor type, treatment (HRQoL)

${ }^{\mathrm{c}}$ Adjusted for age, gender, tumor type (HRQoL)

unemployment or performing charity work (16\%)] (Supplementary Fig. 1). Of those with a (partial) disability pension, 21 out of 28 received full-disability pensions (80-100\% disability).

\section{Determinants for having a paid job or not (Table 2)}

After correcting for relevant confounders, patients diagnosed with Cushing's disease (range OR 2.9-3.3) or acromegaly (OR 2.5-2.7) were more often without a paid job, compared to patients with a NFPA or prolactinoma; had undergone radiotherapy more often compared to no current treatment (OR 3.9); or had one or more endocrine deficits compared to patients without any deficits (OR 2.9-3.6). Furthermore, patients not currently in a relationship were more often without a paid job (OR 2.3), as well as patients with a low or intermediate education (OR 3.0-3.4). When correcting for HRQoL, the relationship between the determinants low education, Cushing's disease, endocrine status and having a job or not remained significant.

\section{Working problems among patients with a paid job (Table 3)}

Patients with a pituitary tumor and a paid job report a median number of 36 working hours per week (IQR 26.0-40.0), which was not significantly different between various tumor types. In total, $41 \%$ of patients with a paid job reported to have missed on average 27.1 (SD 54.5) days during the previous year due to illness (absenteeism) and 39\% of patients reported being bothered by health-related problems during work (range per tumor type: 29-50\%). Among those bothered, there was a significant difference between tumor types regarding performance at work despite health-related problems (presenteeism: mean 6.8, range per tumor type $6.3-8.5, \mathrm{p}=0.03)$. Only 21 patients $(12 \%)$ were under treatment of an occupational physician during the previous year. 
Table 3 Patient and work characteristics among 173 patients of working age with a pituitary tumor and a paid job, stratified per tumor type

\begin{tabular}{|c|c|c|c|c|c|c|c|}
\hline & $\begin{array}{l}\text { Total } \\
(\mathrm{N}=173)\end{array}$ & $\begin{array}{l}\text { NFPA } \\
(\mathrm{N}=50)\end{array}$ & $\begin{array}{l}\text { ACRO } \\
(\mathrm{N}=25)\end{array}$ & $\begin{array}{l}\mathrm{CD} \\
(\mathrm{N}=17)\end{array}$ & $\begin{array}{l}\text { PRL } \\
(\mathrm{N}=77)\end{array}$ & $\begin{array}{l}\mathrm{RCC} \\
(\mathrm{N}=4)\end{array}$ & $\mathrm{p}$-value \\
\hline \multicolumn{8}{|l|}{ SF-HLQ } \\
\hline $\begin{array}{l}\text { Working hours/week, } \\
\text { median (IQR) }\end{array}$ & $36.0(24.0-40.0)$ & $36.0(28.0-40.0)$ & $40.0(32.0-40.0)$ & $32.0(22.0-40.0)$ & $32.0(24.0-40.0)$ & $39.0(29.0-45.0)$ & $0.211^{\mathrm{b}}$ \\
\hline $\begin{array}{l}\text { Bothered by health- } \\
\text { related problems } \\
\text { during work, } \mathrm{N}(\%)\end{array}$ & $68(39.3)$ & $22(44.0)$ & $9(36.0)$ & $5(29.4)$ & $30(39.0)$ & $2(50.0)$ & $0.608^{\mathrm{b}}$ \\
\hline $\begin{array}{l}\text { Performance at work } \\
\text { despite health- } \\
\text { related problems, } \\
\text { mean among those } \\
\text { bothered (SD) } \\
(\text { scale } 1-10)^{\mathrm{a}}\end{array}$ & $6.8(1.7)$ & $6.3(1.6)$ & $7.9(1.4)$ & $7.6(1.5)$ & $6.6(1.7)$ & $8.5(0.7)$ & $0.025^{\mathrm{b}}$ \\
\hline $\begin{array}{l}\text { Absence from work } \\
\text { during the past } \\
\text { year due to health- } \\
\text { related problems, } \\
\mathrm{N}(\%)\end{array}$ & $70(40.5)$ & $25(50.0)$ & $7(28.0)$ & $8(47.1)$ & $27(35.1)$ & $3(75.0)$ & $0.104^{\mathrm{b}}$ \\
\hline $\begin{array}{l}\text { Days absent during } \\
\text { previous year, } \\
\text { median days (IQR) }\end{array}$ & $5.0(4.0-28.0)$ & $10.0(4.0-30.0)$ & $10.0(5.0-35.0)$ & $5(4.5-5.0)$ & $5(3.0-30.0)$ & $10(3.0-130.0)$ & $0.424^{\mathrm{b}}$ \\
\hline \multicolumn{8}{|l|}{ Medical consumption } \\
\hline $\begin{array}{l}\text { Contact with occu- } \\
\text { pational physician, } \\
\mathrm{N}(\%)\end{array}$ & $21(12.1)$ & $8(16.0)$ & $3(12.0)$ & $1(5.9)$ & $8(10.4)$ & $1(25.0)$ & 0.706 \\
\hline \multicolumn{8}{|l|}{ WRFQ (scale 0-100) } \\
\hline $\begin{array}{l}\text { Work scheduling and } \\
\text { output demands, } \\
\text { mean }(\mathrm{SD})^{\mathrm{a}}\end{array}$ & $78.0(28.7)$ & $77.0(28.3)$ & $81.8(27.0)$ & $84.1(29.5)$ & $76.8(28.8)$ & $63.3(52.7)$ & $0.714^{\mathrm{b}}$ \\
\hline $\begin{array}{l}\text { Physical demands, } \\
\text { mean }(\mathrm{SD})^{\mathrm{a}}\end{array}$ & $84.3(27.1)$ & $83.7(28.6)$ & $87.2(25.2)$ & $83.9(24.1)$ & $84.5(26.6)$ & $68.3(54.8)$ & $0.849^{\mathrm{b}}$ \\
\hline $\begin{array}{l}\text { Mental demands and } \\
\text { social demands, } \\
\text { mean }(\mathrm{SD})^{\mathrm{a}}\end{array}$ & $75.6(31.2)$ & $85.2(24.8)$ & $84.0(28.0)$ & $76.6(28.6)$ & $60.7(52.9)$ & $77.9(29.2)$ & $0.380^{\mathrm{b}}$ \\
\hline $\begin{array}{l}\text { Flexibility demands, } \\
\text { mean }(\mathrm{SD})^{\mathrm{a}}\end{array}$ & $79.8(29.1)$ & $76.1(30.3)$ & $86.3(25.2)$ & $84.1(27.9)$ & $79.6(29.0)$ & $68.3(50.6)$ & $0.563^{\mathrm{b}}$ \\
\hline $\begin{array}{l}\text { Index score, mean } \\
(\mathrm{SD})^{\mathrm{a}}\end{array}$ & $78.6(28.1)$ & $77.2(28.6)$ & $83.1(26.5)$ & $85.7(25.4)$ & $77.8(27.1)$ & $50.4(51.3)$ & $0.179^{b}$ \\
\hline
\end{tabular}

NFPA non-functioning pituitary adenoma, $A C R O$ acromegaly, $C D$ Cushing's disease, $P R L$ prolactinoma, $R C C$ Rathke's cleft cyst, $N$ number, $S D$ standard deviation, $I Q R$ interquartile range, $S F-H L Q$ short form-health and labour questionnaire, $W R F Q$ work role functioning questionnaire 2.0

Bold-p $<0.05$

${ }^{\text {a }}$ Higher scores indicate better performance at work

${ }^{\mathrm{b}}$ Corrected for age and gender

The highest percentage of patients reported problems with mental and social demands (i.e. concentrating on work tasks and working without losing train of thought) (Supplementary Table 3, Fig. 2).

\section{Quality of life (Fig. 3)}

In general, HRQoL was significantly higher among patients with a paid job compared to those without a paid job on all domains of the SF-36 (range mean difference 7.6-32.8, $\mathrm{p}<0.05$ ). This was confirmed among patients with acromegaly in a subgroup analysis between patients with and without a paid job, however could only be confirmed for some, but not all domains for patients with other tumor types (NFPA, CD, PRL). 


\section{Total}

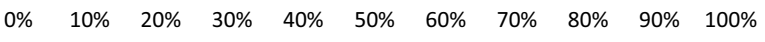
'Get going easily at the beginning of the workday'

'Start on your job as soon as you arrived at work' 'Do your work without stopping to take extra breaks or rests' 'Stick to a routine or schedule'

'Work fast enough' 'Finish work on time' 'Do your work without making mistakes' 'Satisfy the people who judge your work' 'Feel a sense of accomplishment in your work' 'Feel you have done what you are capable of doing' Phyisical demands

'Lift, carry, or move objects at work weighing more than 10 pounds' 'Sit, stand, or stay in one position for longer than 15 min while working' 'Repeat the same motions over and over again while working' 'Bend, twist, or reach while working' 'Use hand-held tools or equipment (for example, a phone, pen, Mental and social demands 'Keep your mind on your work' 'Do work carefully' 'Concentrate on your work' 'Work without losing your train of thought' 'Easily read or use your eyes when working' 'Speak with people in-person, in meetings or on the phone'

'Control your temper around people when working' Flexibility demands 'Set priorities in my work' 'Handle changes in my work' 'Process incoming information, for example e-mails, in time' 'Perform multiple tasks at the same time' 'Be proactive, show initiative in my work'

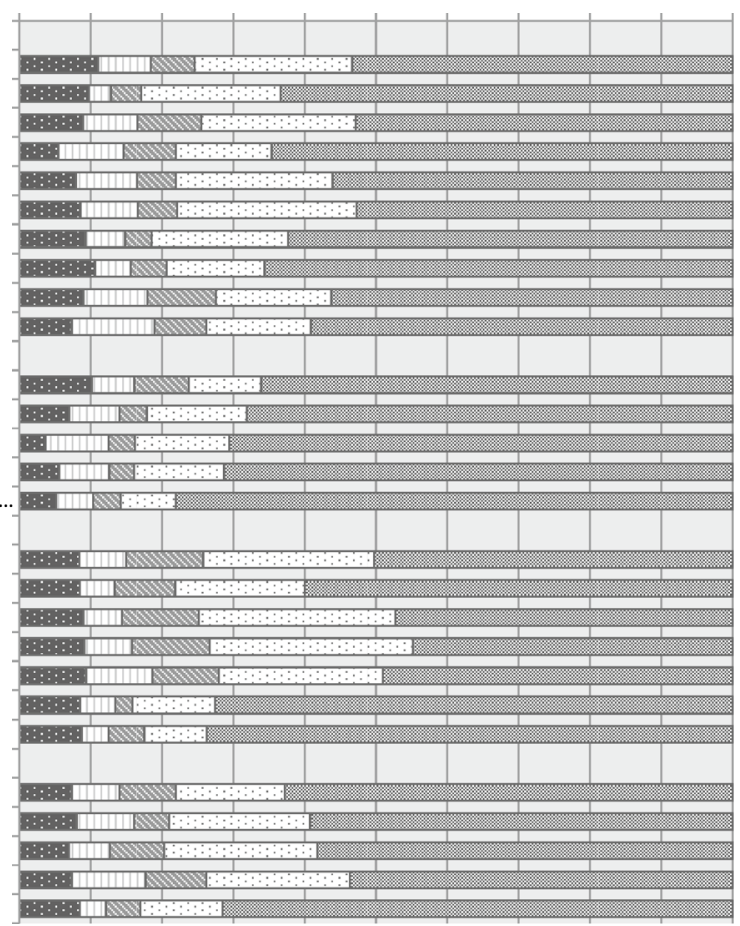

All the time (100\%)

$\square$ Most of the time

Half of the time (50\%)

$\square$ Some of the time

Completely not $(0 \%)$

Fig. 2 Difficulties experienced at work among patients with a paid job

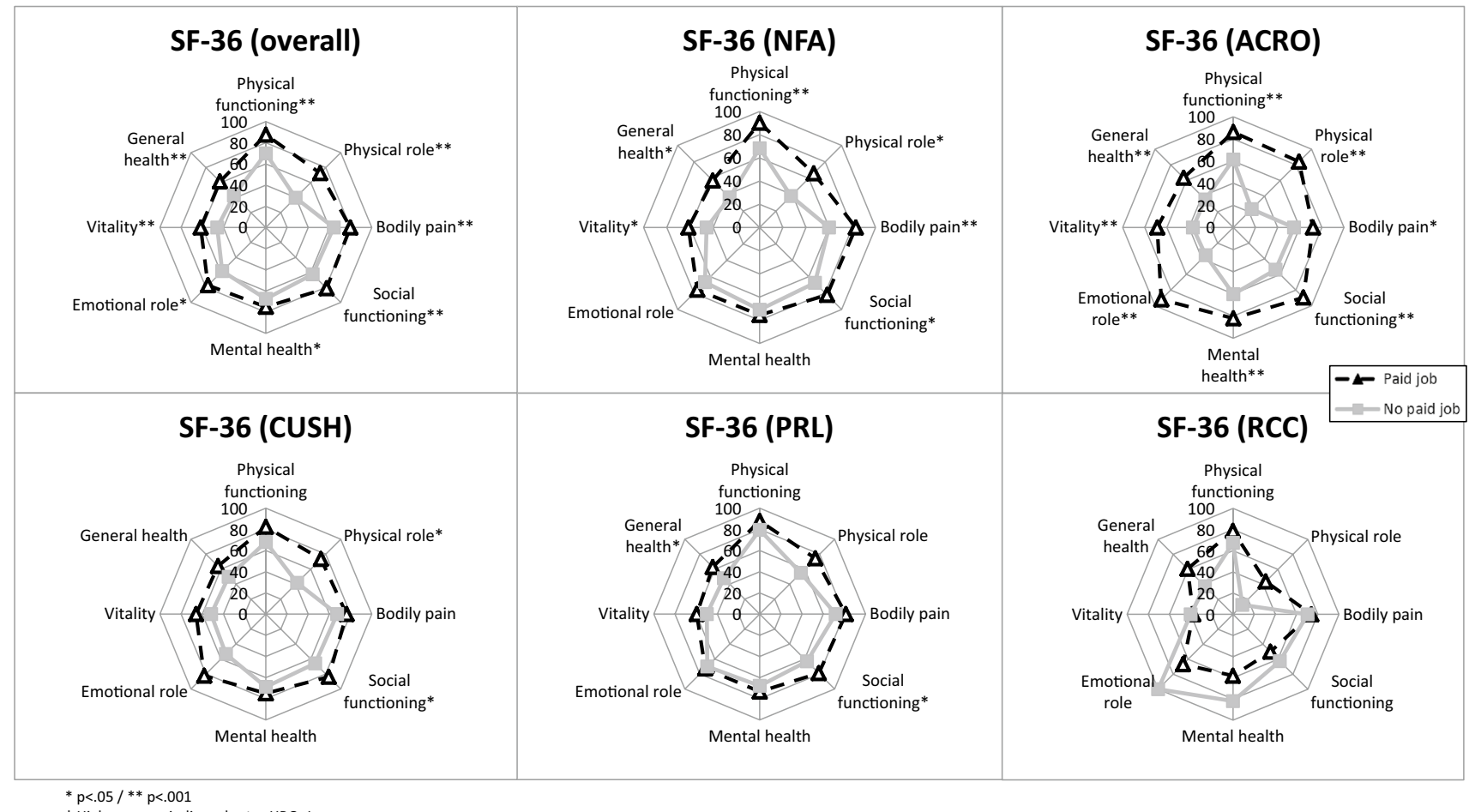

Fig. 3 SF-36 scores in patients with a paid job compared to those without a paid job 


\section{Discussion}

This large cross-sectional study in patients treated for a pituitary tumor and of working age reveals that $32 \%$ of patients do not have a paid job. We found an increased risk of not having a paid job among patients with Cushing's disease, acromegaly, (pan)hypopituitarism and/or those patients that had undergone radiotherapy. In addition, well-known general determinants such as being single or lower education are also valid in this condition. Of those with a paid job, relatively many reported having missed work due to illness during the past year $(41 \%)$ or not performing up to their self-perceived maximum potential (39\%). The most common problems reported by patients concerned mental and social demands of work. This study is the first to look at determinants of (not) having a paid job in patients with a pituitary tumor. Furthermore, to the best of our knowledge, this study represents the largest study to date that looks at work disability and the relationship between job status and HRQoL in this population.

\section{Rates of patients with a paid job}

Data on work disability among patients with a history of a pituitary disease are scarce. The overall rate of $68 \%$ of patients with a paid job found in our study could not be verified in other studies, however, it is lower when compared to the general Dutch population (78.6\%) (matched for age, gender and education) [25]. Two studies reported lower rates of patients with a paid job. Van Roijen et al. studied a cohort of 129 patients with hypopituitarism and found that only $26 \%$ of patients had a paid job [5]. While they did not report data within the same age range, the study also took place in 1989, further limiting comparability. Likewise, Brod et al. showed that $56 \%$ of adult patients with growth hormone deficiency had a paid job, however their results should be interpreted with caution, since they present data of a heterogeneous group of 39 patients, including patients with short stature, brain tumors, and trauma [9].

Among patients with functioning tumors, the reported rates were more comparable to ours. Wagenmakers et al. prospectively studied 123 Dutch patients in remission of CD of whom $51 \%$ had a paid job [8]. While these results are indeed in line with our findings among patients with CD (53\%), the study lacked information exclusively on patients aged 18-65. Short-term outcomes, on the other hand, as found by Pikkarainen et al., were higher $(66 \%$ with a paid job), however the population represented patients with Cushing's syndrome (26 adrenal and 48 pituitary adenomas) and data was collected retrospectively, both limiting interpretability [7].
In contrast to the long-term outcomes, Jahangiri et al. looked at rates prior to diagnosis/treatment, and did not find significant differences between 18 patients with apoplexia compared to 117 patients without apoplexia [26]. These results were also collected retrospectively, had many missing data and lacked long-term results, therefore also limiting comparability of results.

\section{Determinants for not having a paid job}

This study is the first to study determinants for not having a job in a chronic setting of patients with pituitary tumors. We found tumor type, treatment, endocrine status (diseasespecific), marital status, and education level (sociodemographic) to increase the risk of not having a paid job. The disease-specific and sociodemographic determinants found in the present study are in agreement with those affecting HRQoL [1, 27-29] in pituitary and other diseases [30, 31].

In the short-term, Jahangiri et al. did not find a difference between patients with apoplexia and without apoplexia regarding having a paid job or not [6]. A history of apoplexia is probably of less importance in the chronic phase, as well as in functioning tumors.

As anticipated, patients with (pan)hypopituitarism were significantly more often without a paid job compared to those without endocrine deficits. In our analysis hypopituitarism patients performed worse than those with panhypopituitarism. The variable composition of number and severity of the number of deficiencies and replacement status limits the exact interpretation of this finding.

\section{Absenteeism, problems experienced at work and HRQOL}

We found a relatively high percentage of patients (41\%) with absence from work due to health-related reasons during the past year. Regarding the magnitude of absenteeism, our data were skewed, with the median being 5 days per year, whereas the mean was 27.1 days. The latter was considerably higher than that of the average Dutch population (8.8 days per year) (matched for age, gender) [32], however, unfortunately could not be compared to matched controls. In line with our findings, Jonsson et al. found increased sick leave in patients with NFPA (mean leave 40.2 days) compared to age-matched controls (24.0 days) [10], and other studies reported means varying between 19.8 and 38.4 days per year $[5,11,12]$.

The highest percentage of patients without a paid job was among patients with ACRO/CD. The difference in HRQoL between patients with and without a paid job was largest among patients with ACRO (Fig. 3), perhaps indicating the presence of a mild and severe phenotype of patients with ACRO. Previous studies have endorsed these thoughts on 
various subtypes of acromegaly [33-35], however none incorporated the long-term outcomes (as depicted in Tier 3 of the value-based healthcare model [36]) on social participation and sustainability of health, such as work disability.

Prior to the study we had anticipated finding lower overall work functioning scores as measured with the WRFQ, particularly for patients with ACRO and CD. In the total cohort, we indeed found lower average scores compared to those of a large selection of Dutch employees [20], and found scores comparable to those of Dutch cancer survivors [37], which emphasizes the impact of having a pituitary tumor. Unexpectedly, however, the overall WRFQ score showed a nonsignificant higher score among patients with ACRO and CD compared to patients with PRL and NFPA, indicating a trend towards better functioning at work. This seems at odds with the fewer paid jobs among patients with ACRO/CD. Even though it can be postulated that this is due to the smaller numbers, it can also be hypothesized that when patients with ACRO/CD are able to maintain their work, they appreciate their work more and therefore experience fewer work-related problems compared to patients with NFPA/PRL. We also found that the largest proportion of pituitary tumor patients were bothered at work by problems in the mental and social domains, which is in line with difficulties experienced by cancer survivors [38] and patients with rheumatoid arthritis [39].

A notable finding was the relatively low percentage of patients visiting an occupational physician (12\%), despite the fact that quite a lot of patients (40\%) in our study reported being bothered by health-related issues at work during the previous year. In the Netherlands, the occupational physician has the role of case manager to guide patients back to work. While patients in our cohort were in a chronic care setting, potentially explaining the minimal number of visits, this might be a potential target for future interventions.

\section{Strengths and weaknesses}

A clear strength of this study is the large sample of participating patients, enabling comparison between various types of pituitary tumors. A recent study performed by van Lier et al. showed that the use of self-reported information on absenteeism and presenteeism was considered the best way to measure sick leave, quantity and quality of work [40], therefore supporting the results presented here.

The limitations of our study are mostly based on limitations of a cross-sectional cohort study. The non-longitudinal nature of the study leads to unanswered questions whether work disability in patients with pituitary tumors is due to the pituitary tumor or has a different nature, and on the interplay between productivity and quality of life. Another limitation is the single center setting of the study. Since the study took place in the Netherlands, which has relatively high work participation and high social security benefits, the generalizability to other countries might be an issue. The social security benefits in the Netherlands are not the same as but can be compared to systems in Scandinavia and Germany [41]. Due to the high social security benefits in the Netherlands, it could be that we observed higher rates of patients without a paid job compared to countries with lower benefits. This might also lead to more severe work problems in countries with lower social security benefits since these patients are unable to afford losing their jobs, and therefore work beyond their capacity, even though they are actually unable to keep it up.

An additional limitation is the distribution of the education level among participants in our study. Even though we invited all patients with a pituitary tumor, there was a high proportion of highly educated patients among our participants. This might decrease the generalizability of our study and the interpretation of our results, since in general, higher education reduces health-related working problems. Furthermore, the low amount of patients with a RCC patients is a limitation. However, after conducting a sensitivity analysis (excluding RCC from the analysis), no different effect was found.

Though quality of life and functioning are influenced by one's ability to work and vice versa, these aspects are often overlooked in current care. A healthcare provider is not always aware of a patient's employment status, and if so, it is generally difficult for the treating physician to help a patient to improve functioning at work. This emphasizes the relevance of our study and it remains important to realize that the impact of a pituitary tumor on work functioning is high. It is therefore necessary to increase awareness among all healthcare providers involved, including occupational physicians, and use targeted interventions in an effort to reduce work disability/prevent unemployment. Regarding interventions aimed at the problems perceived while being at work, these should focus on mental and social demands of the job in relation to the person's capabilities.

\section{Conclusion}

We have shown that work disability among patients with a pituitary tumor is substantial. Not only are they relatively often without a paid job, sick leave is considerable among those who work, and many patients encounter difficulties at work, mostly regarding the mental and social sphere. The determinants and difficulties at work found in this study could potentially be used for further research and we advise healthcare professionals to take these results into consideration in the clinical guidance of patients. 
Acknowledgements We would like to acknowledge Dr. E. van Zwet for his valuable input for the data analysis.

Funding This study was partially performed with financial support from an ASPIRE young investigator research grant (Pfizer, New York, USA). Pfizer, however, had no involvement in the project; the views expressed in this paper are those of the authors only and do not reflect the views of Pfizer.

\section{Compliance with ethical standards}

Conflict of interest The authors declare that they have no conflict of interest.

Informed consent Informed consent was obtained from all individual participants included in the study.

Ethical approval All procedures performed in studies involving human participants were in accordance with the ethical standards of the institutional and/or national research committee and with the 1964 Helsinki declaration and its later amendments or comparable ethical standards.

Open Access This article is distributed under the terms of the Creative Commons Attribution 4.0 International License (http://creativeco mmons.org/licenses/by/4.0/), which permits unrestricted use, distribution, and reproduction in any medium, provided you give appropriate credit to the original author(s) and the source, provide a link to the Creative Commons license, and indicate if changes were made.

\section{References}

1. van der Klaauw AA, Kars M, Biermasz NR, Roelfsema F, Dekkers OM, Corssmit EP et al (2008) Disease-specific impairments in quality of life during long-term follow-up of patients with different pituitary adenomas. Clin Endocrinol 69(5):775-784

2. Andela CD, Scharloo M, Pereira AM, Kaptein A, Biermasz NR (2015) Quality of life (QoL) impairments in patients with a pituitary adenoma: a systematic review of QoL studies. Pituitary 18:752-776

3. Andela CD, Lobatto DJ, Pereira AM, van Furth WR, Biermasz NR (2018) How non-functioning pituitary adenomas can affect health-related quality of life: a conceptual model and literature review. Pituitary 21(2):208-216

4. Andela CD, Niemeijer ND, Scharloo M, Tiemensma J, Kanagasabapathy S, Pereira AM et al (2015) Towards a better quality of life $(\mathrm{QoL})$ for patients with pituitary diseases: results from a focus group study exploring QoL. Pituitary 18(1):86-100

5. Hakkaart-van Roijen L, Beckers A, Stevenaert A, Rutten FF (1998) The burden of illness of hypopituitary adults with growth hormone deficiency. Pharmacoeconomics 14(4):395-403

6. Jahangiri A, Clark AJ, Han SJ, Kunwar S, Blevins LS, Aghi MK (2013) Socioeconomic factors associated with pituitary apoplexy. J Neurosurg 119(6):1432-1436

7. Pikkarainen L, Sane T, Reunanen A (1999) The survival and wellbeing of patients treated for Cushing's syndrome. J Intern Med 245(5):463-468

8. Wagenmakers MAEM, Netea-Maier RT, Prins JB, Dekkers T, den Heijer M, Hermus ARMM (2012) Impaired quality of life in patients in long-term remission of Cushing's syndrome of both adrenal and pituitary origin: a remaining effect of long-standing hypercortisolism? Eur J Endocrinol 167(5):687-695
9. Brod M, Pohlman B, Højbjerre L, Adalsteinsson JE, Rasmussen MH (2014) Impact of adult growth hormone deficiency on daily functioning and well-being. BMC Res Notes 7:813

10. Jonsson B, Nilsson B (2000) The impact of pituitary adenoma on morbidity. Increased sick leave and disability retirement in a cross-sectional analysis of Swedish national data. Pharmacoeconomics 18(1):73-81

11. Ehrnborg C, Hakkaart-Van Roijen L, Jonsson B, Rutten FF, Bengtsson BA, Rosén T (2000) Cost of illness in adult patients with hypopituitarism. Pharmacoeconomics 17(6):621-628

12. Saller B, Mattsson AF, Kann PH, Koppeschaar HP, Svensson J, Pompen $\mathrm{M}$ et al (2006) Healthcare utilization, quality of life and patient-reported outcomes during two years of GH replacement therapy in GH-deficient adults-comparison between Sweden, The Netherlands and Germany. Eur J Endocrinol 154(6):843-850

13. Weigold A, Weigold IK, Russell EJ (2013) Examination of the equivalence of self-report survey-based paper-and-pencil and internet data collection methods. Psychol Methods 18(1):53-70

14. Dekkers OM, Biermasz NR, Pereira AM, Roelfsema F, van Aken MO, Voormolen JHC et al (2007) Mortality in patients treated for Cushing's disease is increased, compared with patients treated for nonfunctioning pituitary macroadenoma. J Clin Endocrinol Metab 92(3):976-981

15. Dekkers OM, Hammer S, de Keizer RJW, Roelfsema F, Schutte PJ, Smit JWA et al (2007) The natural course of non-functioning pituitary macroadenomas. Eur J Endocrinol 156(2):217-224

16. Biermasz NR, Dekkers OM, Voormolen J, de Keizer RJW, Neelis KJ, Wiggers-de Bruïne FT et al (2008) Transsphenoidal resection of pituitary adenomas: long-term results from the Leiden University Medical Center. Ned Tijdschr Geneeskd 152(47):2565-2570

17. Standaard Onderwijsindeling 2016 - Editie 2017/'18, Centraal Bureau voor de Statistiek, Den Haag/Heerlen 2018, The Netherlands

18. UNESCO Institute for Statistics (2014) International standard classification of education, ISCED-F 2013. Montreal, Canada

19. van Roijen L, Essink-Bot ML, Koopmanschap MA, Bonsel G, Rutten FF (1996) Labor and health status in economic evaluation of health care. The Health and Labor Questionnaire. Int J Technol Assess Health Care 12(3):405-415

20. Abma FI, van der Klink JJL, Bültmann U (2013) The work role functioning Questionnaire 2.0 (Dutch Version): examination of its reliability, validity and responsiveness in the general working population. J Occup Rehabil 23(1):135-147

21. Ware JE, Sherbourne CD (1992) The MOS 36-ltem short-form health survey (SF-36). Med Care 30(6):473-483

22. EuroQoL Group (1990) EuroQol—a new facility for the measurement of health-related quality of life. Health Policy 16(3):199-208

23. Andela CD, Scharloo M, Ramondt S, Tiemensma J, Husson O, Llahana $S$ et al (2016) The development and validation of the Leiden Bother and Needs Questionnaire for patients with pituitary disease: the LBNQ-Pituitary. Pituitary 19(3):293-302

24. Shrier I, Platt RW (2008) Reducing bias through directed acyclic graphs. BMC Med Res Methodol 8(1):70

25. Arbeidsdeelname; kerncijfers. Centraal Bureau voor de Statistiek, D, H/Heerlen. https://opendata.cbs.nl/statline/portal.html? la $=$ nl\&_catalog $=$ CBS\&tableId $=83031$ NED\&_theme $=9$ (2018). Accessed June 4th 2018

26. Jahangiri A, Lamborn KR, Blevins L, Kunwar S, Aghi MK (2012) Factors associated with delay to pituitary adenoma diagnosis in patients with visual loss. J Neurosurg 116(2):283-289

27. Santos A, Resmini E, Martínez MA, Marti C, Ybarra J, Webb SM (2009) Improving quality of life in patients with pituitary tumours. Curr Opin Endocrinol Diabetes Obes 16(4):299-303

28. Webb SM, Badia X, Barahona MJ, Colao A, Strasburger CJ, Tabarin A et al (2008) Evaluation of health-related quality of life in 
patients with Cushing's syndrome with a new questionnaire. Eur J Endocrinol 158(5):623-630

29. van der Klaauw AA, Biermasz NR, Hoftijzer HC, Pereira AM, Romijn JA (2008) Previous radiotherapy negatively influences quality of life during 4 years of follow-up in patients cured from acromegaly. Clin Endocrinol 69(1):123-128

30. van Muijen P, Weevers NLEC, Snels IAK, Duijts SFA, Bruinvels DJ, Schellart AJM et al (2013) Predictors of return to work and employment in cancer survivors: a systematic review. Eur J Cancer Care 22(2):144-160

31. Donker-Cools BHPM, Wind H, Frings-Dresen MHW (2016) Prognostic factors of return to work after traumatic or non-traumatic acquired brain injury. Disabil Rehabil 38(8):733-741

32. Arbeidsdeelname; kerncijfers. Centraal Bureau voor de Statistiek, D, H/Heerlen. https://opendata.cbs.nl/statline/portal.html? $1 \mathrm{a}=\mathrm{nl} \&$ _catalog $=$ CBS $\&$ tableId $=83056$ NED\&_theme $=170$ (2018). Accessed June 4th 2018

33. Asa SL, Kucharczyk W, Ezzat S (2017) Pituitary acromegaly: not one disease. Endocr Relat Cancer 24(3):C1-C4

34. Geraedts VJ, Andela CD, Stalla GK, Pereira AM, van Furth WR, Sievers C et al (2017) Predictors of quality of life in acromegaly: no consensus on biochemical parameters. Front Endocrinol 8:40

35. Trepp R, Everts R, Stettler C, Fischli S, Allemann S, Webb SM et al (2005) Assessment of quality of life in patients with uncontrolled vs. controlled acromegaly using the acromegaly quality of life questionnaire (AcroQoL). Clin Endocrinol 63(1):103-110

36. Porter ME (2014) What is value in health care? N Engl J Med 363(26):2477-2481

37. Abma FI, Bültmann U, Amick Iii BC, Arends I, Dorland HF et al (2018) The work role functioning questionnaire v2.0 showed consistent factor structure across six working samples. J Occup Rehabil 28(3):465-474

38. Mehnert A (2011) Employment and work-related issues in cancer survivors. Crit Rev Oncol Hematol 77(2):109-130

39. van Vilsteren M, Boot CRL, Knol DL, van Schaardenburg D, Voskuyl AE, Steenbeek R et al (2015) Productivity at work and quality of life in patients with rheumatoid arthritis. BMC Musculoskelet Disord 16:107

40. van Lier LI, Bosmans JE, van Hout HPJ, Mokkink LB, van den Hout WB, de Wit GA et al (2018) Consensus-based cross-European recommendations for the identification, measurement and valuation of costs in health economic evaluations: a European Delphi study. Eur J Heal Econ 19(7):993-1008

41. Verstappen SMM, Bijlsma JWJ, Verkleij H, Buskens E, Blaauw AAM, ter Borg EJ et al (2004) Overview of work disability in rheumatoid arthritis patients as observed in cross-sectional and longitudinal surveys. Arthritis Care Res 51(3):488-497 